\title{
La significación del logo a partir de su construcción semiótica y su apoyo en nuevas formas de comunicación digital: El caso de Apple
}

\section{The meaning of the logo from its semiotic construction and its reliance on new formats of digital communication: The case of Apple}

Carmen Llorente-Barroso. Universidad Complutense de Madrid. España.

carmenllorente@ucm.es

$[\underline{\mathrm{CV}}]$ (1) GR

Olga Kolotouchkina. Universidad Complutense de Madrid. España.

olga.kolotouchkina@ucm.es

$[\underline{\mathrm{CV}}] \odot \mathrm{G}^{\mathrm{C}} \mathrm{O}$

Francisco García-García. Universidad Complutense de Madrid y Asociación Científica Icono 14. España.

fghenche@gmail.com

$[\underline{\mathrm{CV}}] \odot \mathrm{R}^{\mathrm{C}} \mathrm{O}$

Esta investigación ha sido realizada por investigadores integrantes del Grupo de Investigación UCM Brand Lab de la Universidad Complutense de Madrid desde el mes de agosto de 2020 hasta el mes de marzo de 2021, dentro de las líneas de interés marcadas por mencionado grupo de investigación.

Llorente-Barroso, C., Kolotouchkina, O., \& García-García, F. (2021). La significación del logo a partir de su construcción semiótica y su apoyo en nuevas formas de comunicación digital: El caso de Apple. Revista Latina de Comunicación Social, 79, 333-356.

https://www.doi.org/10.4185/RLCS-2021-1529

\section{RESUMEN}

Introducción: La importancia de los logos ha postulado la existencia de una semiótica corporativa en cuanto a código general al que responden semióticas locales débilmente codificadas, por la elevada carga simbólica de estos signos visuales. Metodología: Esta investigación pretende profundizar en la construcción semiótica de los logos y analizar su proceso de significación apoyado en nuevas formas de comunicación. Para ello, se propone un análisis interpretativo a partir de un modelo categórico fundamentado en reconocidas teorías previas, que se aplica al caso de Apple como ejemplo de marca de referencia a nivel internacional. Resultados: Los resultados sugieren que las comunidades digitales en torno a la marca estudiada (sean medios propios o ganados) contribuyen a dotar de sentido a estos signos y a culturizarlos; en gran medida, gracias a la colaboración de los propios consumidores. Conclusiones y discusión: Los logos corporativos presentan una estructura sencilla si solamente se atiende a la expresión, pero relacionalmente demuestran una elevada 
complejidad. Son precisamente estas relaciones las que dotan a tales signos de una significación que está en constante evolución, y que, actualmente, encuentra en las redes y en sus usuarios-fans de las marcas, el mejor apoyo. Además, estas conclusiones permiten identificar nuevas vías para la investigación sobre la semiótica corporativa y los procesos de semiosis que implica, bien implementando técnicas metodológicas que permitan completar esta investigación exploratoria, bien atendiendo a perspectivas conectadas a las nuevas tendencias en la gestión de la comunicación de la marca.

PALABRAS CLAVE: Semiótica; logo; marca; identidad visual corporativa; signo; entornos digitales; Apple.

\begin{abstract}
Introduction: The importance of logos has underpinned the existence of a corporate semiotics as a general code to which weakly codified local semiotics respond, due to the high symbolic load of these visual signs. Methodology: This research aims to delve deeper into the semiotic construction of logos and to analyse their process of signification supported by new forms of communication. To this end, an interpretative analysis is proposed based on a categorical model linked to recognised previous theories, which is applied to the case of Apple as an example of a benchmark brand at an international level. Results: The results suggest that online brand communities (whether they are owned or earned media) provide these signs with meaning and make logos to become cultural icons; to a large extent, thanks to the collaboration of the consumers themselves. Conclusions and discussion: Corporate logos present a simple structure if we only look at the expression, but relationally they show a high degree of complexity. It is precisely these relationships that give signs a significance that is constantly evolving, and which currently finds the best support in in online communities of brand followers. Furthermore, these conclusions allow us to identify new avenues for research into corporate semiotics and the processes of semiosis involved, either by implementing methodological techniques that enable us to complete this exploratory research, or by addressing new challenges in the management of brand communication.
\end{abstract}

KEYWORDS: Semiotics; logo; brand; corporate visual identity; sign; digital environments; Apple.

\title{
CONTENIDO
}

1. Introducción. 1.1. El logo asociado a su significación (tipo corporativo). 1.2. La importancia de los espacios digitales en la significación de los logos. 2. Objetivos. 3. Metodología. 4. Resultados: Análisis e interpretación. 4.1. Elementos estructurales del símbolo corporativo de Apple. 4.2. Relaciones entre los elementos del signo de Apple e implicaciones en su significación. 4.3. Proceso de significación del logo de Apple apoyado en formas de comunicación digital. 5. Conclusiones y discusión. 6. Referencias

\section{Introducción}

Los logos responden a un código visual específico que los identifica como signos corporativos, diferenciándolos de otros que responden a la imagen como substancia (fotografía, pintura, etc.). Este código visual autónomo se caracteriza por un marcado simbolismo (Llorente-Barroso, 2008). La semiótica logo-simbólica encajaría con la concepción semiológica de Saussure (1945, p. 60) conectada a "la vida social", y con la perspectiva pragmática y "formal" de Peirce (1974, p. 21).

Greimas (1994) insiste en la existencia de una semiótica figurativa y otra plástica, por la dificultad de que una semiótica pueda abarcar el extenso ámbito de significaciones que reagruparía a las diversas formas de expresión visual. También el Grupo $\mu$ (1993) se refiere a una semiótica icónica 
(figurativa) y otra plástica (no figurativa). Por tanto, dentro de la semiótica visual, además de la semiótica figurativa, es importante tener presente la autonomía de la semiótica plástica, que rearticula los signos figurativos, dotando al discurso de profundidad axiológica (Floch, 1987).

Estas concreciones responden a matizaciones sobre la substancia semiótica, que Hjelmslev (1987) identifica con el sentido tomado por una forma en relación con su significación (Greimas \& Courtés, 1982). En la cultura visual contemporánea, interactúan y conviven substancias muy diversas que motivan variadas formas de producción de sentido, desafiando metodológicamente a los instrumentos semióticos (Demaria, 2010). Específicamente, en lo que se refiere a la substancia semiótica de los logos, el reto se plantea por la débil articulación del código a partir de otros lenguajes como el de la imagen, el del color o el escrito, que lo configuran como "un dialecto, o un idiolecto, del amplio lenguaje de la imagen funcional" (González-Solas, 2002, p. 139).

Hjelmslev (1987) considera que los modelos semióticos ideales se apoyan en una correspondencia biunívoca entre expresión y contenido en sus estratos de forma y substancia. Barthes (1987) resume que el plano de la expresión está formado por los significantes, mientras que los significados corresponden al plano del contenido. Expresión y contenido constituyen dos planos funtivos y solidarios en un signo, ya que no cabe expresión sin contenido ni contenido sin expresión (Hjelmslev 1987). Las semióticas ideales responden a una fuerte codificación y se caracterizan, además de por la diferenciación entre los planos de expresión y de contenido, por relaciones entre las unidades de cada plano sólidamente estabilizadas y tipificadas (Grupo $\mu$, 1993). En general, las semióticas visuales, por la débil formalización de sus planos, su fluidez y su complejidad polisémica (Grupo $\mu$, 1993) como los sistemas culturales, son multidireccionales y se regulan localmente, por lo que su significación no es universal, sino que depende de un contexto cargado de contradicciones y de una praxis interpretativa variable según cada persona (Lorusso, 2015). Pese a ello, el Grupo $\mu$ (1993) opina que los logos más reconocidos por el público funcionan como estereotipos icónicos y responden a semióticas más fuertemente codificadas. Por el contrario, González-Solas (2002) apunta que estos signos visuales solamente se pueden entender por el contrato enunciativo, lo que exige el conocimiento de su contexto.

En el último medio siglo, la semiótica ha constatado la complejidad que esconden los procesos de significación e interpretación de las marcas, que combinan valores diferenciales respecto a otras marcas con valores asociativos relativos a una determinada categoría del mercado (Scolari, 2007). La semiótica ha permitido entender la marca como factor activo en la producción de significados (Semprini, 1995) y como construcción cultural abierta, apoyada en sofisticadas redes de asociación (Conejo \& Wooliscroft, 2015).

Pese a las interesantes aportaciones de la semiótica aplicada al estudio de las marcas, no hay muchas aportaciones que indaguen en las técnicas de significación asociadas a sus logos. Precisamente, el análisis que se propone en esta investigación se focaliza en los procesos de semiosis o producción de significación que subyacen en el código de los logos, desde su perspectiva social y transformadora, es decir, reflexionando sobre la dimensión social de estos signos y su evolución palimpséstica (Lorusso, 2015).

\subsection{El logo asociado a su significación (tipo corporativo)}

El logo es un instrumento que articula el significado de una marca (entendida como tipo corporativo) en relación con otras semióticas corporativas que confieren un sentido a este signo visual (Kelly, 2017). En este caso, el concepto de articulación debe entenderse "como una noción heurística con la que se denominan las relaciones inestables entre prácticas y estructuras, textos y contextos (u otros 
textos)" (Demaria, 2010, p. 16).

Por su parte, el tipo corporativo correspondería a la marca conceptual, es decir, al estereotipo de esa marca extendido entre el público. La marca, en colaboración con el logo que la representa, actúa como "un dispositivo semiótico capaz de producir un discurso, dotarlo de sentido y comunicarlo a los destinatarios" (Scolari, 2007, p. 60). Como tipo corporativo al que refiere el logo, la marca opera como un esquema mental que orienta la interpretación del consumidor, ayudándole a reconocer códigos que le permiten seleccionar aspectos determinantes para dotar a los estímulos de sentido (Polidoro, 2015).

Los logos se han convertido en signos omnipresentes en las semióticas propias de los procesos de globalización (Johannessen, 2018) que, configurados por múltiples elementos visuales (Jiang et al., 2016), proyectan la marca a la que representan e inciden en las actitudes de sus consumidores (Kaur \& Kaur, 2019). La conexión del logo con su significado no es natural para el consumidor, se crea con estructuras de comunicación circundantes a la marca (Kelly, 2017) y gracias al potencial simbólico de sus formas expresivas, que permiten atisbar su sentido corporativo pleno (Llorente-Barroso \& García-García, 2015). Muchas veces, el sentido de los logos, como el de los mensajes publicitarios, se fundamentan en una semiótica semisimbólica, propia de los lenguajes visuales plásticos, y con un fuerte anclaje cultural (Floch, 1987).

La estética de un diseño corporativo puede reforzar estereotipos de valor para los consumidores (Japutra et al., 2018) e incorporar elementos descriptivos del producto que pueden influir en las evaluaciones que los consumidores hacen de las marcas y en sus intenciones de compra (Luffarelli et al., 2019). La tendencia hacia una simplificación del diseño corporativo ha llevado a muchas marcas a apostar por propuestas enmarcadas en el flat design (diseño plano), que suelen conseguir mayores niveles de atención (Mañas-Viniegra et al., 2020b) y de recuerdo (Bonales-Daimiel et al., 2021). La familiaridad y la personalidad de la marca también median en la relación logo-imagen de marca (Kaur \& Kaur, 2019). Además, el prestigio y el valor de la marca revierten en la atención que su logo es capaz de acaparar, siendo las marcas mejor posicionadas en rankings las que acaparan un mayor grado de atención (Mañas-Viniegra et al., 2020a).

Por otro lado, la importancia del logo en la identificación de la marca conlleva que cada cambio en él se interprete como una perturbación en la imagen de marca (Stuart \& Muzellec, 2004), lo que obliga a prevenir a los consumidores, guiando sus expectativas y reduciendo la discrepancia entre nuevos y viejos logos (Grobert et al., 2016).

El público vive inmerso en un mundo de signos que no pueden abarcar la realidad a la que se refieren, pero con una fuerza expresiva que proyecta su significado y con la persistencia necesaria para crear códigos semióticos estables. Así, la construcción retórica del logo como discurso visual, permite entenderlo como símbolo y metáfora metonímica (Hsun \& Jie, 2020; Llorente-Barroso \& García-García, 2015) con un significado estabilizado culturalmente. Al respecto, es preciso recordar que los logos son sensibles al contexto, ya que su significado, vinculado al discurso de identidad de la marca, está condicionado por las convenciones y las variables contextuales (sociales, políticas, culturales, económicas) (Semprini, 1995), combinadas con las impresiones extraídas por los sujetos a partir de sus experiencias reales con la marca (Floch, 2001).

En el universo substancial de la imagen, los logos emergen como objetos evocadores de inmenso potencial asociativo (Sievers, 2017), lo que les permite adquirir un significado vinculado a afectos y sentimientos (Bollas, 2009; Bresciani \& Del-Ponte, 2017). Una vez en la memoria, los logos actúan como imágenes del pensamiento, es decir, como representaciones subjetivas (Daniels-McGhee \& 
Davis, 1994). Sin embargo, los logos también forman parte de la memoria colectiva que se configura a partir de los recuerdos de los miembros que componen un grupo social (Halbwachs, 1992). Desde un punto de vista semiótico, es preciso destacar el "poder de modelización de la memoria", que actúa de forma determinante, tanto desde una perspectiva prospectiva como retrospectiva, modelando los códigos para permitir la reinterpretación de los acontecimientos y los signos en el tiempo (Lorusso, 2015, p. 100).

La semiótica de la marca ha sido abordada a partir de numerosos estudios. Desde una perspectiva semiótica, las marcas se han definido como constructos multidimensionales que albergan grados muy diversos de alcance, autonomía, cocreación y significación (Conejo \& Wooliscroft, 2015). En la construcción del sentido corporativo de una marca, desde una perspectiva generativa, Semprini (1995) y Scolari (2007) proponen tres niveles o espacios de significación:

1. Nivel profundo (o axiológico): En el que se relacionan y oponen los valores corporativos que componen el núcleo de identidad de la marca y condensan su universo de significación.

2. Nivel narrativo: En el que los elementos básicos del núcleo se narrativizan, expresando los roles de la marca desde una perspectiva realista para perfilar sus rasgos fundamentales.

3. Nivel superficial (o discursivo): En el que las narrativas se concretan, asumiendo un carácter específico, a través de la retórica, el contexto y el tiempo, con el fin de ir renovando la producción discursiva de la marca aportando originalidad sin afectar a los valores.

En el estudio semiótico de la marca, Semprini (1995) propone un mapping de los valores de consumo que considera a la marca como un elemento activo en la producción de significado y contempla cuatro puntos de valoración distribuidos en dos ejes (crítico-lúdico y utópico-práctico).

\subsection{La importancia de los espacios digitales en la significación de los logos}

El panorama mediático de la actualidad ha impuesto nuevas estrategias de significación que reivindican la importancia del consumidor en la propia construcción de los signos corporativos. Actualmente, las marcas "no se crean simplemente manipulando enunciados icónicos o lingüísticos, también la experiencia interactiva se convierte en un elemento fundamental de su proceso de construcción" (Scolari, 2007, p. 66). Comunidades y redes sociales ofrecen una posibilidad comunicativa a las marcas implicando a sus seguidores en su propio proceso de significación (Llorente-Barroso et al., 2020).

Una comunidad bien gestionada puede generar niveles muy altos de pasión y compromiso entre los consumidores (Ind et al., 2020). Para mejorar la relación con los usuarios y su fidelidad, los responsables de marketing deben conseguir y mantener el compromiso de los consumidores dentro de las comunidades online de las marcas, gestionando la reputación corporativa (Hanson et al., 2019). Además, los gestores de la marca pueden desarrollar estrategias que motiven su valor y el compromiso de los usuarios según las características de la comunidad, del tipo de relaciones que se establezcan y del perfil del usuario (Weiger et al., 2017).

Entre sus aportaciones, el eWOM (electronic Word of Mouth o boca a oreja en el entorno digital) se está posicionando como una estrategia online clave en la significación y comercialización de las marcas; de hecho, es mucho más eficaz que la publicidad tradicional (Chu \& Kim, 2018), al vincularse a la participación altruista de un consumidor sobre su experiencia con una marca (Reimer \& Benkenstein, 2018). Los usuarios confían en las opiniones difundidas online por otros consumidores que guían sus decisiones de compra (De-Veirman \& Hudders, 2020). El gran aporte que puede implicar el $e W O M$ a la significación de la marca, ha llevado a algunos anunciantes a considerar las plataformas online como parte imprescindible de su estrategia (Kumi \& Sabherwal, 
2019), ideando fórmulas de incentivación de eWOM entre sus usuarios (Stanton et al., 2019).

Un usuario que no sienta compromiso hacia la marca no participará en procesos de eWOM, por lo que el engagement (compromiso que manifiesta el usuario hacia la marca) es un mediador en los entornos digitales que condiciona la participación del consumidor (Black \& Veloutsou, 2017; Kapoor et al., 2018), la interacción marca-usuario, el interés por compartir contenidos sobre esa marca (Segarra-Saavedra \& Hidalgo-Marí, 2018), y un eWOM positivo (Wu \& Wang, 2011). El digital engagement depende, en parte, de cada plataforma (Voorveld et al., 2018), y puede medirse por los likes, comentarios y acciones de los consumidores en estos espacios (Lee et al., 2018). Las marcas que emocionan contribuyen a generar un $e W O M$ positivo más potente e influyente, que se apoya en vínculos sociales fuertes y próximos (Gvili \& Levy, 2018; Lou \& Koh, 2018).

Muchos internautas se declaran voluntarios motivados en la generación eficaz y creativa de contenidos de marca (Black \& Veloutsou, 2017). Según Kaur et al. (2018) las comunidades online vinculadas a la marca generan un valor emocional y social para los usuarios, que determina su participación en estos espacios. Además, las señales de reputación que comunican un papel social de la marca en sus comunidades online suelen resultar eficaces para crear sentimientos de conexión y compromiso con tales comunidades (Hanson et al., 2019). La participación de los consumidores en estos espacios corporativos también se ha relacionado con recompensas intrínsecas que la marca puede ofrecer cuando profundiza en las necesidades y deseos de los consumidores, construyendo un sentido de comunidad y un clima de confianza en estos entornos (Ind et al., 2020). Asimismo, la interactividad característica de estas plataformas incentiva a los usuarios a la cocreación del universo de significación de una marca (Scolari, 2007), que aparece vinculado a su logo.

\section{Objetivos}

Este artículo pretende profundizar en el conocimiento sobre la construcción semiótica de los logos y sus procesos de significación, apoyados en las nuevas formas de comunicación que permite el entorno digital. A partir de este propósito general, se plantean los siguientes objetivos específicos $(\mathrm{OE})$ :

OE1. Identificar los elementos semióticos que componen el logo en cuanto a signo corporativo sujeto a un código específico.

OE2. Estudiar las relaciones entre los elementos estructurales del logo entendido como signo, así como la implicación de tales interacciones en el proceso de significación de estos signos visuales.

OE3. Analizar el proceso de significación que subyace en el logo y se apoya en el engagement de algunas formas de comunicación digital.

\section{Metodología}

El alcance de los objetivos previamente formulados implica un planteamiento metodológico exploratorio, apoyado en un análisis semiótico de tipo interpretativo que se realiza a partir del estudio de un caso ejemplar al que se aplica un modelo de análisis fundamentado en teorías previas. El logo seleccionado es el que representa a la marca de mayor valor internacional según Interbrand (2020): Apple. El análisis de este caso servirá para explicar los procesos de significación que han nutrido de sentido a su logo, vinculándolo a su tipo corporativo (marca), a partir de las contribuciones comunicativas conectadas a la marca.

Para entender el proceso de significación que subyace en la popular manzana mordida de Apple, se propone el estudio de la configuración del tipo corporativo al que remite este reconocido símbolo 
visual, entendido como un signo con una estructura semiótica. De este modo, se propone un análisis semiótico a partir del modelo esbozado por el Grupo $\mu$ (1993), en su obra Tratado del signo visual: Para una Retórica de la Imagen, según las aportaciones de Ogden \& Richards (1923) y Palmer $(1975 ; 1977)$ sobre la articulación de los signos. Así, se plantea un modelo de análisis (Figura 1) que permite explicar el proceso de significación y sentido de los logos desde una aproximación hermenéutica a estos textos visuales, a partir de dos categorías analíticas principales, los elementos estructurales y las relaciones e implicaciones entre tales elementos y respecto a su evolución.

\section{ELEMENTOS ESTRUCTURALES}

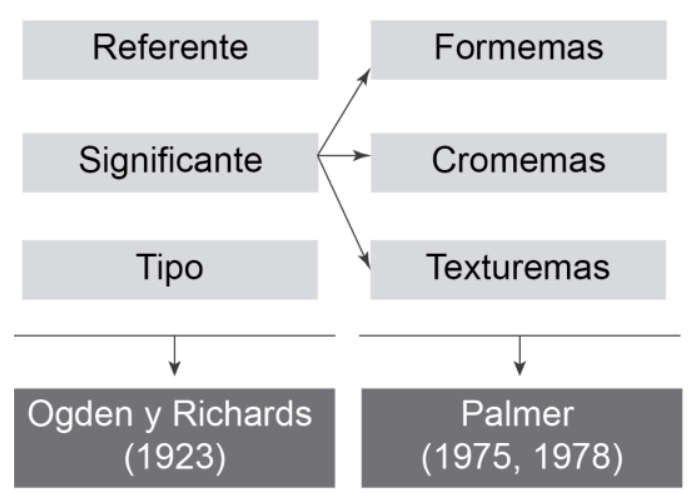

RELACIONES E IMPLICACIONES

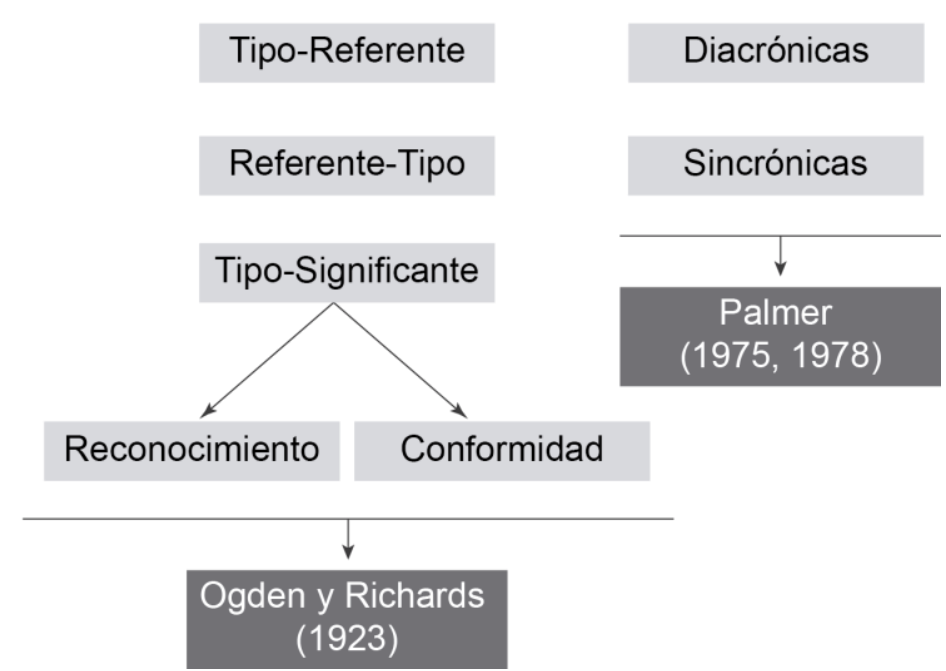

Figura 1: Modelo de análisis del proceso de significación del logo.

Fuente: Elaboración propia a partir del Grupo $\mu$ (1993), Palmer $(1975 ; 1977)$ y Ogden y Richards (1923).

El modelo defendido por el Grupo $\mu$ (1993) para el análisis de los signos plásticos viene a sintetizar el enfoque gestaltista y el enfoque estructuralista que propuso Palmer (1975; 1977), quien consideró una red jerarquizada de unidades estructurales definidas como un conjunto de propiedades globales (enfoque holístico) y organizado en partes o propiedades atómicas (enfoque estructural). Dentro de este enfoque, para el análisis de los elementos estructurales del signo, se diferencian tres categorías de propiedades globales que constituyen las unidades básicas de significación en una potencial semiótica visual:

1. Los formemas, identificadores de la forma. En el caso de los logos, la forma siempre se impone, y aparece definida por los formemas de posición (ubicación de la figura respecto al fondo), dimensión (tamaño por relación al resto de los elementos) y orientación (propiedad del contorno de una forma asimétrica en relación a dos puntos de referencia, foco y fondo). El significado de la forma puede proceder de tres fuentes:

a. La exaltación de uno de tales formemas.

b. La integración de la forma en un sistema culturizado.

c. La relación de estos formemas de un modo único.

2. Los cromemas, identificadores del color. En los signos visuales, el color se articula a partir de los cromemas de dominancia (matiz o tinte), luminosidad (brillo, medido por la cantidad de luz o blanco que tiene el color) y saturación (pureza del color). El significado del color es muy complejo y subjetivo; a menudo, aparece mediado por el contexto socio-cultural, pero también por la armonía y los contrastes en los que se presenta la forma coloreada. 
3. Los texturemas, identificadores de la textura. En la comunicación visual, las texturas requieren la intervención de dos texturemas, el de los elementos repetidos para crear esa textura, y el de la ley de repetición que fija el ritmo sobre el que se apoya la textura. Es una propiedad global prescindible, pero cuando aparece es un elemento significativo porque permite sentir lo que se ve a través del tacto.

El enfoque de Palmer $(1975 ;$ 1977) para el estudio relacional del signo considera que las relaciones y posiciones entre estas unidades estructurales que configuran el logo determinan, en cierta medida, su sentido corporativo. Estas relaciones se definen a partir de las propiedades atómicas del signo, que pueden responder a dos tipos:

1. Relaciones sincrónicas, que se producen cuando existe más de un elemento (coordinación, subordinación y supraordenación).

2. Relaciones diacrónicas, que se vinculan a la evolución temporal del signo.

Por otro lado, la propuesta del Grupo $\mu$ (1993) para el análisis de los signos icónicos se fundamenta en las aportaciones de Ogden y Richards (1923), que consideran la definición del signo según una estructura tripartita y relacional. Según este enfoque, el logo estaría formado por tres elementos estructurales:

1. Un referente o designatum, actualizado y validado por la existencia de un tipo particular y único con el que se corresponde.

2. Un significante o conjunto de estímulos que refieren a un tipo estable y que el público identifica gracias a unos rasgos que asocia a un referente reconocido como hipóstasis del tipo.

3. Un tipo o un modelo interiorizado y estable, que comparten los conocedores de un código y se define como una representación mental, fruto de un proceso de integración que busca la equivalencia entre referente y significante. El tipo es el elemento clave en el signo; de hecho, semiotizar consiste en la generación de tipos o conceptos generales, obviando las características particulares. La interpretación de un signo respecto a un tipo depende de tres factores determinantes (Grupo $\mu, 1993$ ):

a. La presencia de propiedades visuales particulares, que condicionan su decodificación.

b. El contexto visual en el que es percibido y que puede relacionarlo con otros estímulos visuales.

c. El contexto pragmático, impuesto por una ideología y una cultura, que inciden en la interpretación de los signos.

La propuesta de Ogden y Richards (1923) para el análisis relacional del signo plantea que las tres partes del signo pueden interrelacionarse mediante interacciones dobles, destacando dos en los procesos de significación del logo y en las que participa el tipo:

1. La relación referente-tipo busca una estabilización e integración de los rasgos del referente en un tipo; la relación tipo-referente se apoya en la conformidad entre las características del tipo que presenta un referente para determinar si es o no una hipóstasis de ese tipo.

2. La relación tipo-significante puede ser de conformidad cuando el significante es sometido a una prueba que consiste en confrontar lo que se percibe con un repertorio de tipos (paradigmas); o de reconocimiento cuando el significante presenta una serie de estímulos que permiten el reconocimiento del tipo al que corresponden. Estas pruebas están sujetas a la intervención de un repertorio de tipos (tipoteca) que está organizado por oposiciones y diferencias, y es condición sine qua non del carácter semiótico de cualquier hecho visual, ya que permite la necesaria discretización a la que hay que someter al continuo perceptivo para poder interpretar tales hechos visuales. 


\section{Resultados: Análisis e interpretación}

En esta investigación interesa, especialmente, el proceso de significación de los logos según el modelo de análisis previamente explicado (Figura 1). Para satisfacer los objetivos planteados, este análisis conlleva:

1. En relación con el objetivo OE1, la identificación y la interpretación de los elementos semióticos que configuran el símbolo corporativo de Apple entendido como un signo anclado a un código semiótico concreto.

2. Con respecto al objetivo OE2, el estudio de las interacciones entre los elementos estructurales que componen el signo de Apple para entender su importancia en el proceso de significación de este símbolo corporativo.

3. En vinculación con el objetivo OE3, el análisis del apoyo que este proceso de significación encuentra en algunas comunidades virtuales creadas en torno a la marca Apple.

Los resultados obtenidos del análisis y la interpretación de estos tres temas principales se han categorizado según cada una de estas líneas en los subapartados siguientes.

\subsection{Elementos estructurales del símbolo corporativo de Apple}

Según la dimensión más holística del modelo de Palmer $(1975 ; 1977)$ que reinterpreta el Grupo $\mu$ (1993), y en lo que respecta específicamente al logo de Apple, la forma se define según sus formemas, que son las propiedades más importantes en la significación de esta marca a partir de su emblema visual. La orientación imperturbable de la manzana mordida en todas las manifestaciones de la marca determina su estabilidad. Esta invariabilidad no se preserva ni en la posición ni en la dimensión del logo, que depende del soporte en el que aparezca y se adapta a las necesidades comunicativas de cada caso. La manzana mordida (diferente a la del pecado original o a una mera fruta) actúa como fuente semántica y permite identificarla como un signo visual corporativo único, fuertemente culturizado y en el que se exalta la simplicidad formal del símbolo (Figura 2).
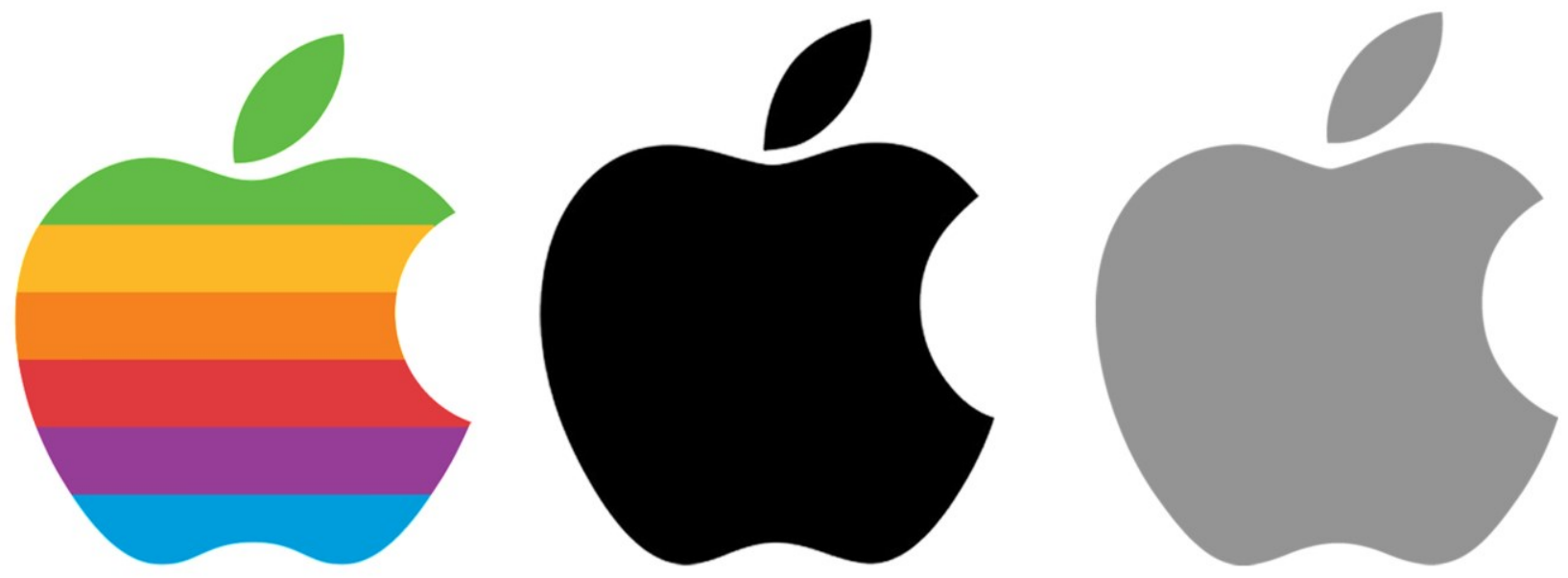

Figura 2: Forma y cromática del logo de Apple.

Fuente: Apple (1976-2021).

Se ha demostrado que el atractivo de la proporción áurea es transcultural, existiendo una preferencia innata por los logos que, además de inspirarse en este principio, se apoyan en la naturaleza (Pittard et al., 2007). Concretamente, el diseño del logo de Apple se apoya en una forma natural que respeta la proporción 2:3:5, extraída de la secuencia de Fibonacci para la proporción áurea, lo que facilita su identificación y recuerdo (Rizaldi \& Anthonius, 2020). Pese a tratarse de una forma con significado 
corporativo propio, este sentido lo ha adquirido por relación a los significados que simbólicamente acaparó. Así, el logo de Apple transmite una forma de ser en la cultura cibernética contemporánea que, en vinculación a la historia bíblica a la que recuerda, rememora el drama de la tentación ante el avance tecnológico (Rix, 2014). El color de este signo visual no es determinante en la significación actual de la marca, aunque sí lo fue la del logo diseñado por Janoff en 1977 (Figura 2) (Burns, 2018); aquel multicromatismo ha quedado en la mente de los fans de la marca que siguen compartiéndolo en sus comunidades digitales. Hoy, el logo adquiere monocromáticos planos y neutros, que empezó a utilizar a finales de la década de 1990 (Figura 2), a menudo dependientes del soporte en el que aparecen, por lo que los cromemas (dominancia, luminosidad y saturación) varían según este soporte (Figura 3). Precisamente es el soporte lo que determina la existencia de ciertas texturas en la manzana mordida. La textura del logo no es un elemento identitario del logo actual de Apple; no hay un texturema visual que invite a una sensación táctil; tales texturas dependen del material sobre el que aparece el logo (metal o plástico), habitualmente, jugando con acabados mate o pulidos que motivan una presencia sutil y elegante de este signo, dotando de prestigio a la marca (Figura 3).

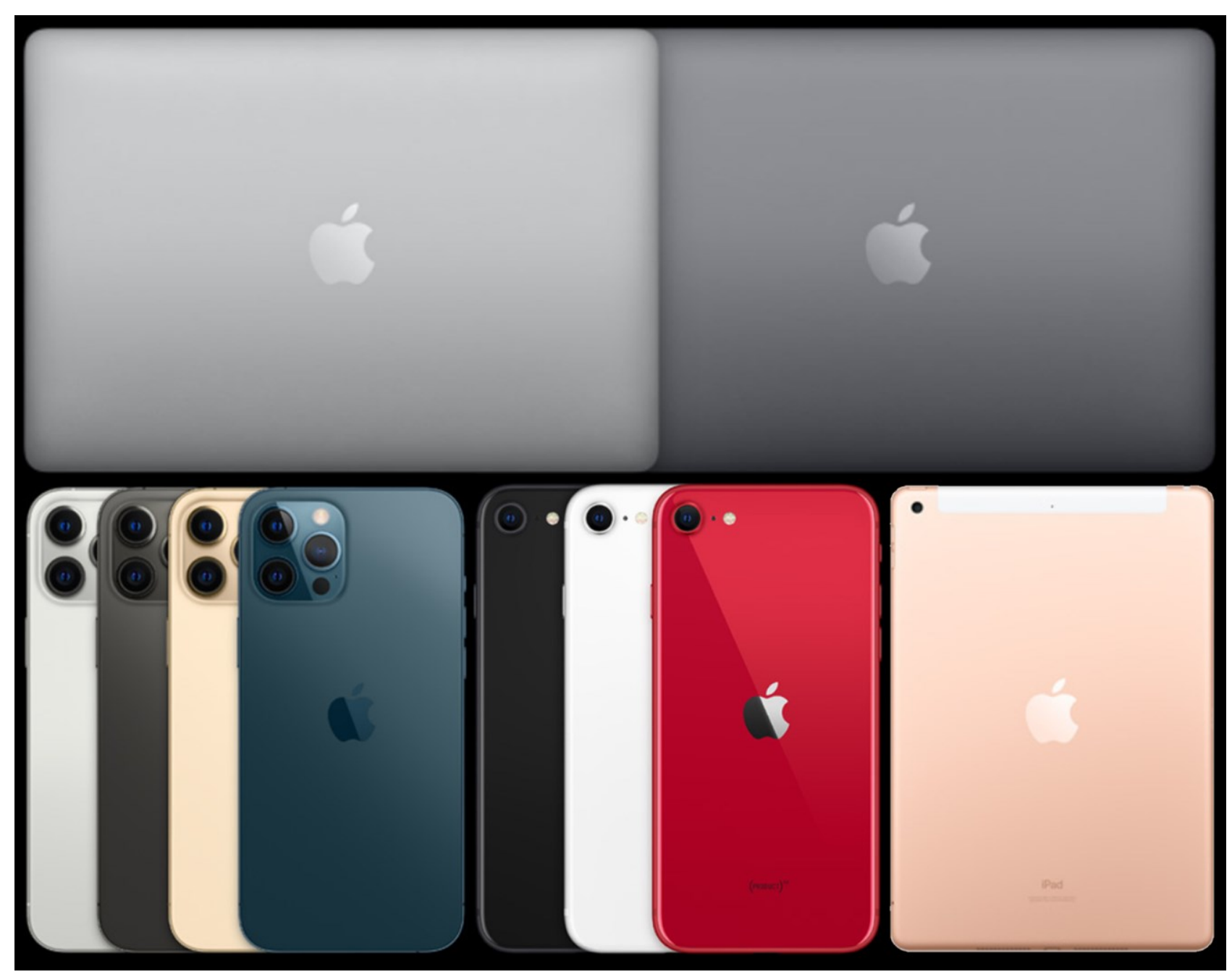

Figura 3: Apariencia del logo en los productos actuales de la marca Apple.

Fuente: Apple (2021a).

En lo que respecta al estudio semiótico que propone el Grupo $\mu$ (1993), apoyándose en las consideraciones de Ogden y Richards (1923), se puede determinar que, de forma general, el tipo conceptual en los signos corporativos (logos) no suele corresponder con el tipo establecido a nivel cultural para esa forma significante. El símbolo corporativo de Apple emerge como paradigma 
identitario para sus consumidores y actúa como un signo de estructura tripartita y relacional. El significante del logo proyecta un concepto que el público ha interiorizado y asocia significativamente a una marca tecnológica. Esta asociación que facilita la significación del símbolo visual a un concepto corporativo, en cierta medida, ha sido construida gracias al esfuerzo comunicativo que ha realizado la marca, pero también a las aportaciones que el propio público realiza en los entornos digitales, ya estén directa (medios propios) o indirectamente (medios ganados ${ }^{1}$ ) vinculados a la marca. Apple ha conseguido asociar todo el concepto de su marca a un signo visual conectado de forma natural a un referente real totalmente distinto y alejado del ámbito tecnológico. Su significante corresponde a la forma de una fruta. Sin embargo, la marca ha logrado dotarlo de un significado corporativo que hoy se reconoce a nivel internacional. Apostar por un signo visual cuyo significante remite a un referente con un tipo conceptual en el consumidor, tiene una parte positiva y una parte negativa para la marca. Desde un punto de vista positivo, la marca se aprovecha de los estímulos visuales con referente real para facilitar la memorización del significante a nivel expresivo, dado que el público ya tiene en su repertorio mental un tipo conceptual que se corresponde con el significante de "manzana mordida". Desde un punto de vista negativo, para conseguir que el receptor asocie ese significante, preexistente al nacimiento de la marca, a otro significado diferenciado de la manzana como una categoría de fruta, y relacionado con un concepto corporativo único y exclusivo, la marca debe realizar un esfuerzo comunicativo continuado y apoyado en la transmisión de significación entre generaciones. En este sentido, Conejo y Wooliscroft (2015) apuntan que únicamente después de que los significantes de la marca se hayan dado a conocer y hayan sido procesados por sus públicos de interés, significantes y marca adquirirán significados compartidos en forma de imagen de marca.

De esta forma, Apple apuesta por un signo que ya responde a un tipo conceptual para el consumidor, permitiendo a la marca aprovecharse de estímulos visuales que facilitan la memorización del significante, pues, como se ha mencionado, el receptor tiene en su repertorio mental un tipo que se corresponde con el de "manzana mordida".

\subsection{Relaciones entre los elementos del signo de Apple e implicaciones en su significación}

En el proceso de significación que adquiere el logo de Apple también hay que considerar las diversas relaciones que benefician a la propia construcción del signo corporativo, a las que se refiere el Grupo $\mu$ (1993) siguiendo el modelo de articulación del signo propuesto por Palmer $(1975 ; 1977)$. En el caso del logo de Apple, al estar constituido por un único elemento visual, no se puede considerar que emerjan relaciones síncronas; además, las que existían en el logo que combinaba el símbolo con el naming (nombre de la marca) tampoco eran de gran relevancia, pues los dos elementos reiteraban la referencia al mismo concepto, "manzana". Sin embargo, existe una relación diacrónica que está relacionada con la simplificación del sello inicial de 1976, que representaba a la marca respecto al diseño en el que se apoya el logo actual que propuso Janoff en 1977 (Aziz, 2013; Burns, 2018). El logo de 1977 prescinde de la complejidad que encerraba el sello previo, diseñado por Ronald Wayne, cofundador de Apple, y en el que se veía a Newton bajo un manzano (Newton crest logo) (Aziz, 2013) (Figura 4). Pese a las importantes diferencias expresivas que existen entre estos dos logos, el original (1976) es solamente un año más antiguo que la manzana mordida de Apple (1977), cuya forma se mantiene intacta, siendo su cromática la que se ha simplificado (Figura 4). La relación diacrónica entre ambos diseños se apoya precisamente en la manzana como elemento visual significativo para la marca desde sus inicios. Esta trasformación del logo de la marca refleja la

\footnotetext{
${ }^{1}$ Dentro de la clasificación POEM (paid, owned and earned media) que diferencia a los medios como pagados, propios o ganados, según su dominio y responsabilidad (Bretón, 2015), los earned media o medios ganados son los que la marca anunciante consigue sin pagar por ellos, ya que han sido generados por terceros. Precisamente por ello, se trata de medios a los que el consumidor suele dar más valor y credibilidad (Gibs \& Bruich, 2010).
} 
evolución de sus propios productos, en una apuesta hacia la simplificación para equilibrar innovación y funcionalidad (Rix, 2014).

En el aporte de significación de esta relación al logo de Apple, la memoria es determinante, no solamente como almacén de conocimientos, sino, especialmente, como instrumento de trabajo para redefinir el pasado y traducirlo en el presente, permitiendo un diálogo entre usuario, pasado y logo (texto) para recuperar el sentido, inevitablemente, filtrado por el esquema cultural de cada usuario (Lorusso, 2015). Esta "persistencia de la memoria en la trayectoria de los tiempos permite que haya historia, en cuanto a recuerdo y en cuanto a conexión de los tiempos" (García-García et al., 2021, p. 1106) también en el reconocimiento de las marcas asociadas a su logo.
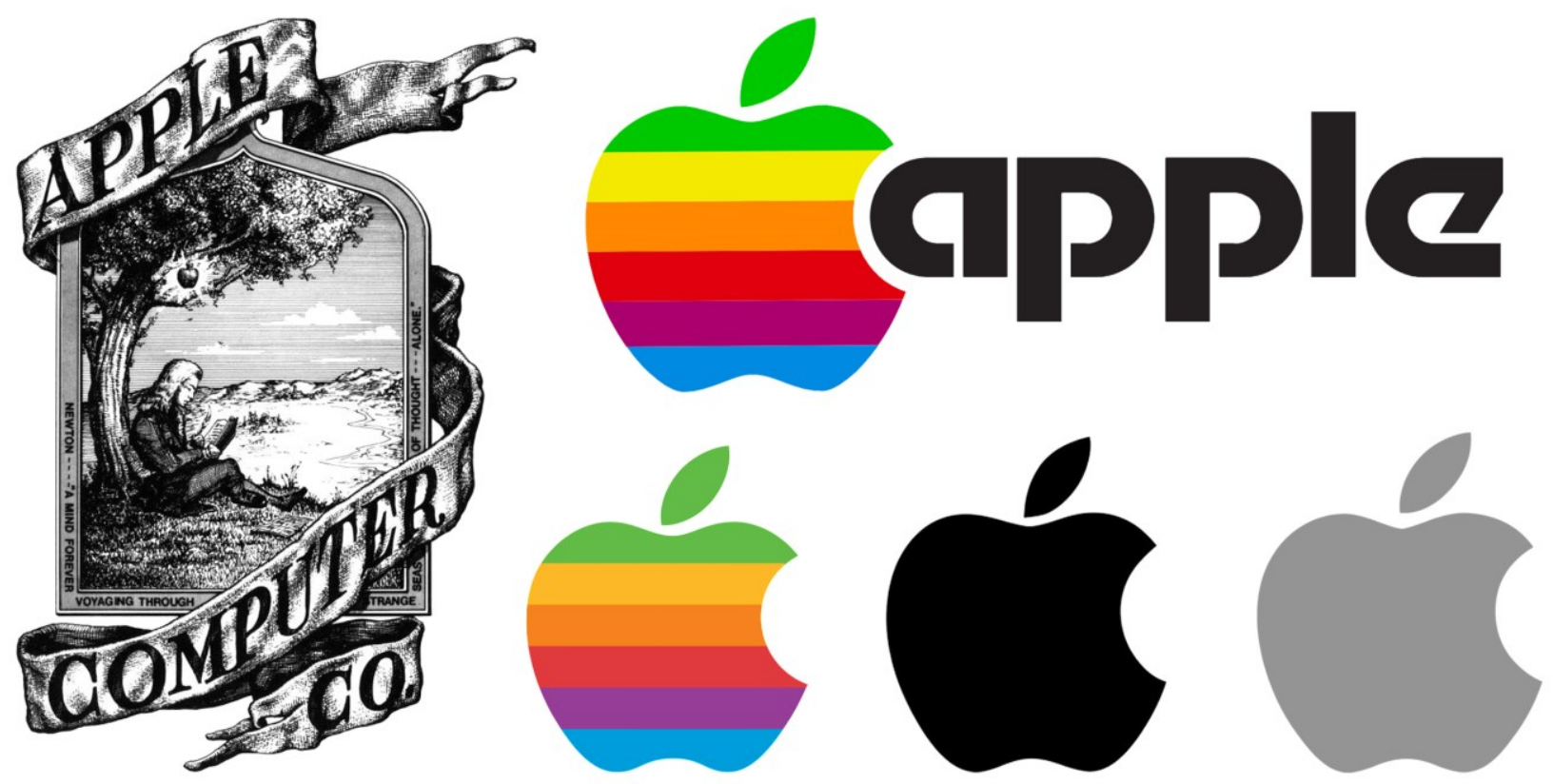

Figura 4: Logos Apple.

Fuente: Apple (1976-2021).

Por otro lado, las relaciones que plantea el Grupo $\mu$ (1993), según las consideraciones de Ogden y Richards (1923), permite interpretar la existencia de dos relaciones dobles o bidireccionales en el estudio semiótico del logo de Apple:

1. La relación referente-tipo permite el desarrollo conceptual de la marca (tipo) a partir del logo (significante) y vinculándolo a un nuevo referente (compañía, productos, etc.). Esta relación permite procesar e integrar todas las aportaciones de la marca o vinculadas a ella, provengan o no de la misma y tengan o no voluntad comunicativa por su parte. Así, Apple ha alcanzado una representación visual que, aunque formalmente figurativa (una manzana), adquiere un sentido diferente de gran potencial simbólico, pero vinculado a un tipo corporativo ya culturizado.

2. La relación tipo-referente, en este caso, se fundamenta en la prueba de conformidad entre los atributos que caracterizan al tipo de la marca, Apple (referente tecnológico a nivel internacional), y su capacidad para representar a un referente real, de modo que, particularmente para los fans de esta marca, ese referente real es una hipóstasis del concepto de marca (tipo), aunque puede superar la verdadera realidad de la marca tecnológica idealizando un referente a partir del tipo que este perfil de usuarios mantienen de la marca.

3. En la relación significante-tipo se reconoce el tipo de la marca Apple a partir del significante, sometiendo al logo (significante-estímulo) a una prueba de reconocimiento, según la cual el 
receptor asocia los estímulos que componen el logo a un tipo de su repertorio (manzana mordida) para darle un significado concreto (marca tecnológica).

4. La relación tipo-significante permite al consumidor determinar si el significante es una hipóstasis del tipo Apple, sometiéndole a una prueba de conformidad, a partir de la cual comprueba si sus características son conformes o no al tipo correspondiente para dotarle de un significado. En este caso, el receptor se fija en las cualidades visuales del tipo específico para hacerlo corresponder al significante percibido que, aunque próximo en atributos expresivos a otros (en este caso una fruta), tiene elementos diferenciales suficientes para contener un significado completamente diferente.

\subsection{Proceso de significación del logo de Apple apoyado en formas de comunicación digital}

Todos estos procesos de significación están influenciados por los discursos que rodean a la marca y emergen de los propios consumidores en las comunidades digitales. Los comentarios que los usuarios comparten sobre la marca en estos espacios permiten cocrear diversos significados alrededor de esa marca (Conejo \& Wooliscroft, 2015) que quedan asociados a su logo. Muchos de los sitios creados por fans de la marca incluyen en su propio nombre una referencia a la misma; entre los listados por Price (2019) que cumplen esta característica y, además, aparecen en el top ten del ranking de Feedspot (2021) están las indicadas en la Tabla 1.

Tabla 1. Comunidades digitales focalizadas en contenidos de la marca Apple.

\begin{tabular}{|c|c|c|c|}
\hline \multirow{4}{*}{$\begin{array}{l}\text { Nombre } \\
\text { 9to5Mac } \\
\text { 9to5mac.com }\end{array}$} & \multirow{4}{*}{$\begin{array}{l}\text { Descripción } \\
\text { Principales contenidos: Noticias, comentarios y guías. } \\
\text { Número de publicaciones: } 23 \text { posts diarios. } \\
\text { Lanzamiento: } 2007 \text {. }\end{array}$} & \multicolumn{2}{|c|}{ Métricas de impacto } \\
\hline & & Social engagement & $1.9 \mathrm{~K}$ \\
\hline & & Domain authority & 92 \\
\hline & & Alexa rank & $4.9 \mathrm{~K}$ \\
\hline \multirow{3}{*}{$\begin{array}{l}\text { AppleInsider } \\
\text { appleinsider.com }\end{array}$} & \multirow{3}{*}{$\begin{array}{l}\text { Principales contenidos: Noticias, comentarios y foros. } \\
\text { Número de publicaciones: } 19 \text { posts diarios. } \\
\text { Lanzamiento: } 1997 \text {. }\end{array}$} & Social engagement & $2.5 \mathrm{~K}$ \\
\hline & & Domain authority & 89 \\
\hline & & Alexa rank & $9.7 \mathrm{~K}$ \\
\hline \multirow{3}{*}{$\begin{array}{l}\text { MacRumors } \\
\text { macrumors.com }\end{array}$} & \multirow{3}{*}{$\begin{array}{l}\text { Principales contenidos: Noticias, comentarios y foros. } \\
\text { Número de publicaciones: } 6 \text { posts diarios. } \\
\text { Lanzamiento: } 2000 \text {. }\end{array}$} & Social engagement & $3.6 \mathrm{~K}$ \\
\hline & & Domain authority & 91 \\
\hline & & Alexa rank & $4.4 \mathrm{~K}$ \\
\hline \multirow{3}{*}{$\begin{array}{l}\text { iMore } \\
\text { imore.com }\end{array}$} & \multirow{3}{*}{$\begin{array}{l}\text { Principales contenidos: Noticias, comentarios y foros. } \\
\text { Número de publicaciones: } 30 \text { posts diarios. } \\
\text { Lanzamiento: } 2008 \text {. }\end{array}$} & Social engagement & 22 \\
\hline & & Domain authority & 88 \\
\hline & & Alexa rank & $6.0 \mathrm{~K}$ \\
\hline \multirow{3}{*}{$\begin{array}{l}\text { Cult of Mac } \\
\text { cultofmac.com }\end{array}$} & \multirow{3}{*}{$\begin{array}{l}\text { Principales contenidos: Noticias, comentarios y foros. } \\
\text { Número de publicaciones: } 17 \text { posts diarios. } \\
\text { Lanzamiento: } 2005 \text {. }\end{array}$} & Social engagement & 48 \\
\hline & & Domain authority & 86 \\
\hline & & Alexa rank & $32.4 \mathrm{~K}$ \\
\hline \multirow{3}{*}{ Macworld } & \multirow{3}{*}{$\begin{array}{l}\text { Principales contenidos: Noticias, comentarios y consejos. } \\
\text { Número de publicaciones: } 4 \text { posts diarios. } \\
\text { Lanzamiento: } 1997 \text {. }\end{array}$} & Social engagement & 161 \\
\hline & & Domain authority & 86 \\
\hline & & Alexa rank & $8.8 \mathrm{~K}$ \\
\hline
\end{tabular}

Fuente: Elaboración propia a partir de Price (2019), Feedspot (2021) y los sitios web de estas comunidades.

Los parámetros de impacto recogidos en la Tabla 1 son determinantes para entender la influencia de estos entornos en la significación de la marca asociada a su logo, y miden desde la participación de los usuarios hasta la popularidad y el posicionamiento en buscadores de estas plataformas (Feedspot, 2021):

1. El social engagement (compromiso del usuario hacia la marca en redes sociales) mide la participación según las acciones, gustos y comentarios del público sobre la marca en medios sociales digitales.

2. El domain authority (autoridad del dominio) permite la clasificación de un site (página web) a 
partir de la predicción de su posicionamiento en buscadores; la puntuación de esta métrica varía entre 1 y 100 , de modo que un mayor valor indica una mejor clasificación.

3. El Alexa rank mide la popularidad del site combinando el tráfico estimado a esta web con la participación de sus usuarios en los últimos tres meses; la primera posición del ranking corresponde a la más popular.

Muchas de las plataformas recogidas en la Tabla 1 cuentan con la colaboración de usuarios experimentados y conocedores de los productos de Apple que actúan como microinfluencers (pequeños influenciadores) tecnológicos y potenciales prescriptores de la marca en estos entornos. Este tipo influencer (influenciador) es más económico y eficaz que las celebrities (famosos) sin conocimientos sobre los productos de la marca; se definen como usuarios reconocidos de forma activa en una comunidad, y se caracterizan por dirigirse a una audiencia de tamaño limitado y con alto engagement (Rakoczy et al., 2018).

Las comunidades virtuales que nacen alrededor de la marca se parecen a los clubs de fans, que ofrecen información actualizada sobre los productos y/o servicios de la marca o aportan críticas que ayudan a esa marca a mejorar (Scolari, 2007). El valor emocional juega un papel clave en la participación de los usuarios en estos espacios, ya que suelen tener necesidades vinculadas al disfrute, la intimidad y la identificación con la comunidad, factores que influyen en su interacción (Kaur et al., 2018). Dentro de las conversaciones que contribuyen a engrandecer el logo de la marca, generando interacción entre usuarios, se puede mencionar el post de Michael Potuck (2021), en 9to5Mac, en el que enseña a otros seguidores a escribir este signo visual, utilizando los teclados de iPad, iPhone y Mac. También destaca la crítica de Tim Hardwick (2021), en MacRumors, sobre el extraño diseño del iPhone 11 Pro con el logo descentrado; o la aportación de Luke Dormehl (2021), en Cult of Mac, a la historia de la marca sobre la modernización de su logo "arcoíris". Así, los logos se incorporan al sistema semiótico de la marca, apoyando la generación de valor para los usuarios y la sociedad, mediante un intercambio de significados creados conjuntamente (Conejo \& Wooliscroft, 2015).

Conscientes de la importancia que tiene el consumidor para la propia imagen y la configuración de un tipo conceptual positivo asociado a su logo, Apple ha incorporado, en su web corporativa (medio propio), dos iniciativas importantes:

1. Los Apple user groups, que potencian la reunión entre sus consumidores de todo el mundo en grupos de proximidad para resolver sus dudas e, incluso, para entablar una amistad apoyada en su afinidad por la marca (Apple, 2021c). Estos grupos que, emergieron a finales de la década de 1970 y alcanzaron su apogeo en la de 1990, configurarían la columna vertebral de sus primeros fieles (Benner, 2015). Aunque conforman un anacronismo en una actualidad en la que Apple ofrece soporte técnico online, siguen siendo prueba de una férrea lealtad a esta marca (Benner, 2015).

2. Las Apple support communities, en las que la marca propone a sus consumidores aprender, compartir experiencias y conocimientos sobre sus productos, y hacerse reconocer en la mayor comunidad oficial de fans de la marca (Apple, 2021b). La marca lanzó esta iniciativa en 2011, como un espacio social de soporte que se centra en el usuario y sus necesidades respecto a sus productos (Kessler, 2011). De este modo, Apple demuestra su interés por el eWOM poniéndose al servicio de sus clientes.

Mediante estas iniciativas de la propia marca, Apple quiere potenciar que consumidores de sus productos en todo el mundo puedan reunirse para resolver sus dudas y establecer un vínculo apoyado en su admiración a la marca (Apple, 2021b; 2021c). Pese a sus ventajas, Hanson et al. (2019) perciben que la configuración de las Apple support communities podría mejorar, evolucionando de 
su sencilla estructura de etiquetas hacia un esquema que comunique con más claridad los contenidos y oriente mejor los comportamientos requeridos a cada perfil de usuario. Estos espacios, creados por la marca, deben generar una cultura comunitaria positiva, en la que los usuarios disfruten de libertad de expresión y desarrollen un sentimiento comunitario vehiculizado por un intercambio de beneficios intrínsecos para motivar la cocreación desde la óptica del placer (Ind et al., 2020) y el hedonismo (Nikolinakou \& Phua, 2020).

Tanto las comunidades generadas por los admiradores de la marca como las que ha creado Apple, se configuran como espacios narrativos con un "universo semántico propio" que los usuarios incorporan a "su lenguaje cotidiano" y contribuyen a crear a través de sus experiencias interactivas, enriqueciendo el significado de la marca (Scolari, 2007, p. 79) asociado a su emblema gráfico.

\section{Conclusiones y discusión}

La principal conclusión que se extrae de este trabajo es que la construcción semiótica de los logos a partir del análisis del símbolo corporativo de Apple permite hablar de un signo asociado a una imagen de marca culturizada; este signo, por tanto, responde a un código autónomo con sus propias normas de interpretación y diferenciado de otros códigos visuales, pero en el que subyace un proceso de significación.

Los resultados específicos obtenidos del análisis interpretativo permiten extraer una serie de conclusiones en conexión con los objetivos formulados en el apartado de metodología. Estas conclusiones sintetizan la originalidad y el aporte de esta investigación a un mejor y más profundo conocimiento sobre la semiótica de los logos corporativos y los procesos de significación y semiosis que implica este código:

1. Los logos presentan una estructura sencilla y simplificada atendiendo a su expresión visual. En esta estructura, los formemas que componen el significante son los elementos estructurales (propiedades globales) más determinantes, por la importancia de la forma para contener el significado corporativo de la marca y proyectarlo. Este significante no refiere a un referente con el que guarde un parecido físico (no existe, en este caso, una relación de cotipia descriptiva), de hecho, la complejidad del tipo corporativo de Apple reside en que no corresponde al de una fruta mordida, sino a todo un ideario corporativo que representa la identidad de una marca tecnológica de referencia internacional.

2. Sin embargo, estos signos visuales, demuestran una complejidad que atiende a las múltiples relaciones que les dotan de significación. Las relaciones de este tipo conceptual de la marca Apple con el significante y el referente son las que permiten un proceso de semiosis que confiere sentido corporativo y cultural a su logo en una continua evolución de la marca. De ahí, la importancia de las relaciones diacrónicas en la semiótica de los logos. En el caso de Apple, el vínculo entre el logo actual y los que existieron antes es esencial para perfeccionar el tipo conceptual al que remite este signo visual.

3. En este proceso de semiosis del signo para la creación de un significado evolutivo, las comunidades virtuales y los contenidos que en ellas vierten sus usuarios son de capital interés en la actualidad. En el caso específico de Apple, el gran número de foros, blogs o comunidades sociales que congregan a usuarios fieles a la marca, convierte a estos espacios en archivos digitales al acceso de los consumidores para determinar su actitud frente a la marca, dotando a su emblema de referencia de un sentido. Así, el eWOM emerge como un instrumento clave para la marca y para la significación que adquiere su significante por excelencia, su logo, lo que merecería investigaciones específicas que ayudaran a las marcas a la incentivación de un $e W O M$ positivo y su buena gestión. 
Además, gran parte de la originalidad de esta propuesta reside en el diseño de un modelo de análisis semiótico, a partir de contribuciones teóricas clásicas que, tradicionalmente, se han focalizado en el estudio de otro tipo de signos. Este modelo sirve como instrumento analítico aplicable a otros logos o discursos visuales culturizados, planteando una alternativa al mapping de los valores de consumo de Semprini (1995) para el estudio de la marca, en este caso, en conexión con su logo. Esta propuesta permite, desde la identificación y el análisis de los elementos estructurales del signo corporativo (logo), hasta la observación de los procesos de significación que subyacen, no solamente en las relaciones entre sus partes y sus tiempos, sino también en la intervención de las interacciones digitales entre las marcas y sus usuarios.

Estos resultados abren todo un campo a la reflexión sobre la importancia de las nuevas formas de comunicación que permiten al consumidor contribuir en los procesos de significación de las marcas representadas visualmente por su logo (Llorente-Barroso et al., 2020). La comunicación de los usuarios a través de las comunidades virtuales reproduce significados compartidos que son asociados a un logo y nutren un sistema social en la línea que apunta Vidales-Gonzáles (2020). Estos espacios online dan a las marcas la oportunidad de implicar a sus usuarios en la producción de su significado corporativo. En este sentido, el eWOM emerge como un instrumento de marketing esencial (Stanton et al., 2019) para las marcas en manos de los consumidores, quienes, al difundir reseñas, experiencias o valoraciones sobre sus productos y/o servicios, generan significado de marca y motivan o frenan su compra y consumo. Para involucrar al consumidor en procesos de difusión de contenidos positivos sobre la marca (eWOM positivo), ese consumidor debe manifestar engagement hacia esa marca (Black \& Veloutsou, 2017; Kapoor et al., 2018; Wu \& Wang, 2011).

En las sociedades globalizadas y digitalizadas, los logos se han convertido en signos omnipresentes de las semióticas actuales (Johannessen, 2018). Su complejidad no radica tanto en una simplificada expresión con capacidad de acaparar grandes niveles de atención en la representación de las grandes marcas (Mañas-Viniegra et al. 2020a; 2020b), sino más bien en su potencial significación, apoyada en su capacidad simbólica (Llorente-Barroso \& García-García, 2015). La interacción usuario-logo es necesaria para poder entender estos signos, y requiere de procesos de semiosis anclados al propio sistema socio-cultural (Vidales-Gonzáles, 2020). La semiótica de cada logo se incorpora al sistema semiótico de su respectiva marca, que se configura como depósito y vehículo de significados colectivos relativos a esa marca (Conejo \& Wooliscroft, 2015). En este sentido, las semióticas corporativas se incorporan a la cultura según un procedimiento palimpséstico que permite acumular los recuerdos en capas de la memoria dotándoles de sentido en cada momento (García-García et al., 2021; Lorusso, 2015).

Las limitaciones de este artículo responden a las propias de los análisis exploratorios a través de estudios de caso. En cambio, los resultados permiten abrir nuevos campos de exploración. Por ejemplo, dada la importancia que está adquiriendo la Responsabilidad Social Empresarial (RSE) para las marcas, se podría profundizar en el impacto que tienen las corrientes de sostenibilidad (Castillo \& Villagra, 2019; Mayorga-Gordillo \& Añaños-Carrasco, 2020) en el proceso de significación de sus logos, según la consideración de los públicos sobre este tipo de acciones en los entornos digitales. Por otro lado, esta investigación exploratoria podría replicarse en el análisis interpretativo de otros símbolos corporativos para completar los resultados obtenidos en este trabajo. Asimismo, sería interesante plantear otras metodologías que completaran este estudio semiótico, utilizando técnicas cuantitativas o cualitativas que incluyeran una percepción de primera mano por parte del público sobre los procesos de significación de los logos. 


\section{Referencias}

Apple (2021a). Apple [web corporativa]. https://apple.co/30Qg8x6

Apple (2021b). Apple support communities [web corporativa]. Apple. https://apple.co/3vMa8RE

Apple (2021c). Apple user groups [web corporativa]. Apple. https://apple.co/3Bd5m0u

Apple (1976-2021). Identidad visual corporativa de Apple.

Aziz, J. T. (2013, 28 de noviembre). The evolution of the Apple logo. Tribune. https://bit.ly/3np9NjX

Barthes, R. (1987). El susurro del lenguaje: Más allá de la palabra y la escritura. Paidós Ibérica.

Black, I., \& Veloutsou, C. (2017). Working consumers: Co-creation of brand identity, consumer identity and brand community identity. Journal of Business Research, 70, 416-429. https://doi.org/10.1016/j.jbusres.2016.07.012

Benner, K. (2015, 8 de septiembre). Mac user groups fade in number and influence, but devotees press on [noticia online]. The New York Times. https://nyti.ms/3vIdYuU

Bollas, C. (2009). The infinite question. Routledge.

Bonales-Daimiel, G., Mañas-Viniegra, L., \& Jiménez-Gómez, I. (2021). El impacto del flat design en el reconocimiento de marcas automovilísticas. Grafica, 9(18), 105-113. https://doi.org/10.5565/rev/grafica.205

Bresciani, S., \& Del-Ponte, P. (2017). New brand logo design: Customers' preference for brand name and icon. Journal of Brand Management, 24(5), 375-390. https://doi.org/10.1057/s41262$\underline{017-0046-4}$

Bretón, M. (2015). ¿Qué son los medios pagados, propios y ganados? Marketing digital. Mariabretongallego. https://bit.ly/3CkROBC

Burns, W. (2018, 26 de marzo). Rob Janoff and the fascinating true story behind his original Apple logo design [noticia online]. Forbes. https://bit.ly/3vMaAzk

Castillo, I., \& Villagra, N. (2019). La comunicación de la RSE. Análisis del sector hotelero. Revista Latina de Comunicación Social, (74), 1580-1609. https://www.doi.org/.4185/RLCS-2019-1400

Chu, S. C., \& Kim, J. (2018). The current state of knowledge on electronic word-of-mouth in advertising research. International Journal of Advertising, 37(1), 1-13. https://doi.org/10.1080/02650487.2017.1407061

Conejo, F., \& Wooliscroft, B. (2015). Brands defined as semiotic marketing systems. Journal of Macromarketing, 35(3), 287-301. https://doi.org/10.1177/0276146714531147 
Daniels-McGhee, S., \& Davis, G. R. (1994). The imagery-creativity connection. Journal of Creative Behavior, 28(3), 151-176. https://doi.org/10.1002/j.2162-6057.1994.tb01189.x

Demaria, C. (2010). Entre textos y practicas: Hacia una semiótica culturológica. En G. Abril (Ed.). El cuarto bios. Estudios sobre comunicación e información (pp. 13-33). Editorial Complutense.

De-Veirman, M., \& Hudders, L. (2020). Disclosing sponsored Instagram posts: The role of material connection with the brand and message-sidedness when disclosing covert advertising, International Journal of Advertising, $39(1), \quad$ 94-130. https://doi.org/10.1080/02650487.2019.1575108

Dormehl, L. (2021, 27 de agosto). Today in Apple history: Rainbow Apple logo gets a modern overhaul. Cult of Mac. https://bit.ly/3b82ZkO

Feedspot (2021, 19 de abril). Top 100 Apple blogs on Mac, iPhone, iPad, Apple TV, Watch \& Music in 2020 [blog]. Feedspot. https://bit.ly/3EenQzI

Floch, J. M. (1987). Semiótica plástica e linguagem publicitária. Análise de um anúncio da campanha de lançamento do cigarro "News". Significação, 6, 29-50. https://doi.org/10.11606/issn.2316-7114.sig.1985.90495

Floch, J. M. (2001). Semiotics, marketing and communication: Beneath the signs, the strategies. Palgrave Macmillan.

García-García, F., Llorente-Barroso, C., \& García-Guardia, M. L. (2021). Interrelaciones de la memoria con la creatividad y la imagen en la conformación de la cultura. Arte, Individuo y Sociedad, 33(4), 1095-1116. https://doi.org/10.5209/aris.70216

Gibs, J., \& Bruich, S. (2010, 20 de abril). Nielsen/Facebook report: The value of social media ad impressions. Nielsenwire. https://bit.ly/314rbDf

González-Solas, J. (2002). Identidad visual corporativa: La imagen de nuestro tiempo. Síntesis.

Greimas, A. J. (1994). Semiótica figurativa y semiótica plástica. En G. Hernández-Aguilar (1994). Figuras y estrategias: En torno a una semiótica de lo visual (pp. 17-42). Siglo XXI Editores y Benemérita Universidad Autónoma de Puebla.

Greimas, A. J., \& Courtés, J. (1982). Semiótica: Diccionario razonado de la teoría del lenguaje. Gredos.

Grobert, J., Cuny, C., \& Fornerino, M. (2016). Surprise! We changed the logo. Journal of Product \& Brand Management, 25(3), 239-246. https://doi.org/10.1108/JPBM-06-2015-0895

Grupo $\mu$ (1993). Tratado del signo visual: Para una retórica de la imagen. Cátedra.

Gvili, Y., \& Levy, S. (2018). Consumer engagement with eWOM on social media: The role of social capital. Online Information Review, 42(4), 482-505. https://doi.org/10.1108/OIR-05-2017-0158

Halbwachs, M. (1992). On collective memory. University of Chicago Press. 
Hanson, S., Jiang, L., \& Dahl, D. (2019). Enhancing consumer engagement in an online brand community via user reputation signals: A multi-method analysis. Journal of the Academy of Marketing Science, 47, 349-367. https://doi.org/10.1007/s11747-018-0617-2

Hardwick, T. (2021, 12 de abril). Images depict 'extremely rare' iPhone 11 Pro with misaligned Apple logo. MacRumors. https://bit.ly/311CITF

Hjelmslev, L. (1987). Ensayos lingüísticos, Tomo II. Gredos.

Hsun, W. P., \& Jie, G. (2020). Systematic creation of a city's visual communication: Logo design based on the phoenix flower in Tainan city. Visual Communication, Pre-print June 2020, 1-18. https://doi.org/10.1177/1470357220917438

Ind, N., Coates, N., \& Lerman, K. (2020). The gift of co-creation: What motivates customers to participate. Journal of Brand Management, 27, 181-194. https://doi.org/10.1057/s41262-019$\underline{00173-7}$

Interbrand (2020). Best global brands 2019 rankings. https://bit.ly/3CdpPnd

Japutra, A., Molinillo, S., \& Wang, S. (2018). Aesthetic or self-expressiveness? Linking brand logo benefits, brand stereotypes and relationship quality. Journal of Retailing and Consumer Services, 44, 191-200. https://doi.org/10.1016/j.jretconser.2018.06.015

Jiang, Y., Gorn, G. J., Galli, M., \& Chattopadhyay, A. (2016). Does your company have the right logo? How and why circular- and angular-logo shapes influence brand attribute judgments. Journal of Consumer Research, 42, 709-726. https://doi.org/10.1093/jcr/ucv049

Johannessen, C. M. (2018). The challenge of simple graphics for multimodal studies: Articulation and time scales in fuel retail logos. Visual Communication, 17(2), 163-185. https://doi.org/10.1177/1470357217746811

Kapoor, K. K., Tamilmani, K., Rana, N. P., Patil, P., Dwivedi, Y. K., \& Nerur, S. (2018). Advances in social media research: Past, present and future. Information Systems Frontiers, 20(3), 531-558. https://doi.org/10.1007/s10796-017-9810-y

Kaur, P., Dhir, A., Rajala, R., \& Dwivedi, Y. (2018). Why people use online social media brand communities: A consumption value theory perspective. Online Information Review, 42(2), 205221. https://doi.org/10.1108/OIR-12-2015-0383

Kaur, H., \& Kaur, K. (2019). Connecting the dots between brand logo and brand image". AsiaPacific Journal of Business Administration, 11(1), 68-87. https://doi.org/10.1108/APJBA-06$\underline{2018-0101}$

Kelly, M. (2017). Analysing the complex relationship between logo and brand. Place Branding and Public Diplomacy, 13(1), 18-33. https://doi.org/10.1057/pb.2016.3

Kessler, T. (2011, 17 de abril). Apple launches Apple support communities [noticia online]. C|Net. https://cnet.co/2ZtnTZt 
Kumi, R., \& Sabherwal, R. (2019). Knowledge sharing behaviour in online discussion communities: Examining behaviour motivation from social and individual perspectives. Knowledge and Process Management, 26(2), 110-122. https://doi.org/10.1002/kpm.1574

Lee, D. Hosanagar, K., \& Nair, H. S. (2018). Advertising content and consumer engagement on social media: Evidence from Facebook. Management Science, 64(11), 5105-5131. https://doi.org/10.1287/mnsc.2017.2902

Llorente-Barroso, C. (2008). Análisis semiótico del logo de Mozilla. Revista de la Sociedad Española de Estudios de la Comunicación Iberoamericana (SEECI), XI(17), 17-56. https://doi.org/10.15198/seeci.2008.17.17-56

Llorente-Barroso, C., \& García-García, F. (2015). The rhetorical construction of corporate logos. Arte, Individuo y Sociedad, 27(2), 289-309. https://doi.org/10.5209/rev ARIS.2015.v27.n2.44667

Llorente-Barroso, C., García-Guardia, M. L., \& Kolotouchkina, O. (2020). El impacto de las redes sociales en la estrategia de las marcas: Creatividad, engagement y eWOM. En S. LiberalOrmaechea \& L. Mañas-Viniegra (Coords.). Las redes sociales como herramienta de comunicación persuasiva (pp. 35-53). McGraw-Hill.

Lorusso, A. M. (2015). Cultural semiotics: For a cultural perspective in semiotics. Palgrave Macmillan. https://doi.org/10.1057/9781137546999

Lou, L., \& Koh, J. (2018). Social media advertising effectiveness: A conceptual framework and empirical validation. Asia Pacific Journal of Information Systems, 28(3), 183-203. https://doi.org/10.14329/apjis.2018.28.3.183

Luffarelli, J., Mukesh, M., \& Mahmood, A. (2019). Let the logo do the talking: The influence of logo descriptiveness on brand equity. Journal of Marketing Research, 56(5), 862-878. https://doi.org/10.1177/0022243719845000

Mañas-Viniegra, L., González-Villa, I. A., \& Llorente-Barroso, C. (2020a). The corporate purpose of Spanish listed companies: Neurocommunication research applied to organisational intangibles. Frontiers in Psychology, 11, 2108. https://doi.org/10.3389/fpsyg.2020.01705

Mañas-Viniegra, L., Santos-Silva, D., \& Liberal-Ormaechea, S. (2020b). The visual-digital identity of corporate brands: A study of neuromarketing in young people from Spain and Portugal. Trípodos, (48), 135-151. https://doi.org/10.51698/tripodos.2020.48p135-151

Mayorga-Gordillo, J., \& Añaños-Carrasco, E. (2020). Atributos de la personalidad de marca socialmente responsable. Revista Latina de Comunicación Social, (75), 97-120. https://www.doi.org/10.4185/RLCS-2020-1418

Nikolinakou, A., \& Phua, J. (2020). Do human values matter for promoting brands on social media? How social media users' values influence valuable brand-related activities such as sharing, content creation, and reviews. Consumer Behaviour, 19(1), 13-23. https://doi.org/10.1002/cb.1790

Ogden, C. K., \& Richards, I. A. (1923). The meaning of meaning: A study of the influence of language upon thought and of the science of symbolism. Routledge \& Kegan Paul. 
Palmer, S. E. (1977). Hierarchical structure in perceptual representation. Cognitive Psychology, 9(4), 441-474. https://doi.org/10.1016/0010-0285(77)90016-0

Palmer, S. E. (1975). Visual perception and world knowledge: Notes on a model of sensorycognitive interaction. En D. A. Norman \& D. E. Rumelhart (Eds.). Explorations in cognition (pp. 279-307). Freeman.

Peirce, C. S. (1974). La ciencia de la Semiótica. Nueva Visión SAIC.

Pittard, N., Ewing, M., \& Jevons, C. (2007). Aesthetic theory and logo design: Examining consumer response to proportion across cultures. International Marketing Review, 24(4), 457-473. https://doi.org/10.1108/02651330710761026

Polidoro, P. (2015). Umberto Eco and the problem of iconism. Semiotica, 206, 129-160. https://doi.org/10.1515/sem-2015-0020

Potuck, M. (2021, 20 de agosto). How to type the Apple logo on Mac, iPhone, and iPad. 9to5Mac. https://bit.ly/3mdUxqG

Price, D. (2019, 17 de diciembre). 28 Websites every Apple fan must bookmark. MUO. https://bit.ly/3Csw5I1

Rakoczy, M. E., Bouzeghoub A., Lopes Gancarski A., \& Wegrzyn-Wolska K. (2018). In the search of quality influence on a small scale - micro-influencers discovery. En H. Panetto, C. Debruyne, H. Proper, C. Ardagna, D. Roman \& R. Meersman (Eds.), On the move to meaningful Internet systems. OTM 2018 Conferences. OTM 2018. Lecture Notes in Computer Science, 11230. Springer.

Reimer, T., \& Benkenstein, M. (2018). Not just for the recommender: How eWOM incentives influence the recommendation audience. Journal of Business Research, 86, 11-21. https://doi.org/10.1016/j.jbusres.2018.01.041

Rix, C. (2014). Bitten. Branded. Bought. The Apple logo in popular culture and the bible. Society of Biblical Literature (SLB) Annual Meeting. Oklahoma Christian University. https://bit.ly/3b9UExc

Rizaldi, M., \& Anthonius, R. (2020). Development phase of 2:3:5 ratio as a visual composition technique on logo design. Proceedings of the International Conference of Innovation in Media and Visual Design (IMDES 2020). Advances in Social Science, Education and Humanities Research, 502, 21-26. https://doi.org/10.2991/assehr.k.201202.048

Saussure, F. (1945). Curso de lingüística general. Losada.

Scolari, C. (2007). Googlemanía. Las marcas on-line y el caso Google. En P. Capriotti (Ed.). Gestión de la marca corporativa (pp. 59-83). La Crujía.

Segarra-Saavedra, J., \& Hidalgo-Marí, T. (2018). Viralidad e interacción. Análisis del engagement de los diez anuncios más vistos en YouTube en España en 2016. Icono14, 16(1), 47-71. https://doi.org/10.7195/ri14.v16i1.1069

Semprini, A. (1995). El marketing de la marca. Una aproximación semiótica. Paidós. 
Sievers, B. (2017). A photograph of a little boy seen through the lens of the associative unconscious and collective memory. Psychoanalysis, Culture \& Society, 22(1), 69-86. https://doi.org/10.1057/pcs.2016.3

Stanton, S. J., Kim, J., Thor, J. C., \& Deng, X. (2019). Incentivized methods to generate electronic word-of-mouth: Implications for the resort industry. International Journal of Hospitality Management, 78, 142-149. https://doi.org/10.1016/j.ijhm.2018.11.004

Stuart, H., \& Muzellec, L. (2004). Corporate makeovers: Can a hyena be rebranded? Journal of Brand Management, 11(6), 472-482. https://doi.org10.1057/palgrave.bm.2540193

Vidales-Gonzáles, C. E. (2020). Semiótica, cultura y comunicación. las bases teóricas de algunas confusiones conceptuales entre la semiótica y los estudios de la comunicación. Razón y Palabra, 66. https://bit.ly/3EkNEu5

Voorveld, H. A. M., Van-Noort, G., Muntinga, D. G., \& Bronner, F. (2018). Engagement with social media and social media advertising: The differentiating role of platform type. Journal of Advertising, 47(1), 38-54. https://doi.org/10.1080/00913367.2017.1405754

Weiger, W. H., Wetzel, H. A., \& Hammerschmidt, M. (2017). Leveraging marketer-generated appeals in online brand communities: An individual user-level analysis. Journal of Service Management, 28(1), 133-156. https://doi.org/10.1108/JOSM-11-2015-0378

Wu, P. C. S., \& Wang, Y. C. (2011). The influences of electronic word-of-mouth message appeal and message source credibility on brand attitude. Asia Pacific Journal of Marketing and Logistics, 23(4), 448-472. https://doi.org/10.1108/13555851111165020 


\section{AUTORES}

\section{Carmen Llorente-Barroso}

Departamento de Ciencias de la Comunicación Aplicada. Universidad Complutense de Madrid.

Doctora en Publicidad y Comunicación Audiovisual por la Universidad Complutense de Madrid (UCM) y Premio Extraordinario de Doctorado 2009-2010. Sus líneas de investigación se focalizan en el estudio de las claves visuales de las marcas, y en la comunicación orientada al envejecimiento activo y a la inclusión de las personas con discapacidad. Actualmente, participa en los proyectos PROVULDIG2-CM (H2019/HUM-5775) y COMPENSA (PID2019-105398RB-C21). Sus investigaciones se han difundido en congresos internacionales y publicaciones en SPI, WoS y Scopus. En 2014, realizó estancia de investigación en Haas School of Business (UC, Berkeley), financiada con una Beca "José Castillejo" (CAS14/00052). Su trayectoria investigadora ha sido reconocida con un Sexenio de Investigación por la CNEAI. Actualmente, es PDI en la Universidad Complutense de Madrid (UCM).

carmenllorente@ucm.es

Î́ndice H: 13

Orcid ID: 0000-0001-7710-0956

Google Scholar: https://scholar.google.com/citations?user=jdsAFJYAAAAJ\&hl=es

ResearchGate: https://www.researchgate.net/profile/Carmen-Barroso

Scopus ID: 55652402000

Academia.edu: https://ucm.academia.edu/CARMENLLORENTEBARROSO

\section{Olga Kolotouchkina}

Departamento de Ciencias de la Comunicación Aplicada. Universidad Complutense de Madrid.

Doctora en Ciencias de la Comunicación y profesora de Comunicación y Branding en la Universidad Complutense de Madrid. Es miembro de la American Academy of Advertising, ECREA e International Place Branding Association. Sus intereses de investigación incluyen el ámbito de place branding, la visibilidad de la discapacidad, la participación ciudadana y la diplomacia pública. Participa en los proyectos "La Diplomacia Pública de las Mega-Ciudades Iberoamericanas: Estrategias de Comunicación y Poder Blando para influir en la legislación ambiental global" (RTI2018-096733-B-I00), y "Rise Women with disabilities in social engagement" (H2020-MSCARISE-2015-690874). Sus investigaciones se han difundido en congresos internacionales y publicaciones en SPI, WoS y Scopus. Ha sido profesora invitada en la Universidad de Toronto y la Universidad Waseda de Tokio.

olga.kolotouchkina@ucm.es

Índice $\mathrm{H}: 5$

Orcid ID: 0000-0002-8348-8544

Google Scholar: https://scholar.google.es/citations?hl=es\&user=GcObyH4AAAAJ

ResearchGate: https://www.researchgate.net/profile/Olga-Kolotouchkina

Scopus ID: 57160276600

Academia.edu: https://ucm.academia.edu/OlgaKolotouchkina

\section{Francisco García-García}

Departamento de Teorías y Análisis de la Comunicación. Universidad Complutense de Madrid.

Catedrático Emérito en la Universidad Complutense de Madrid (UCM). Sus líneas de investigación están vinculadas a la Narrativa Audiovisual, la Publicidad, la Creatividad, la Retórica, las TIC aplicadas a la Comunicación y la Educación. Director de más de 180 Tesis, ha sido profesor de todas las etapas educativas. Dirigió el Centro Nacional de Información y Comunicación Educativas del Ministerio de Educación, Cultura y Deporte (23/10/2000-31/12/2004). Premio Nacional de 
RLCS, Revista Latina de Comunicación Social, 79, 333-356. [Investigación] DOI: 10.4185/RLCS-2021-1529 | ISSN 1138-5820| Año 2021

investigación educativa (1978). Presidente de la Asociación Científica Icono14 y coeditor de las revistas científicas Icono14 y Prisma Social. Ha sido IP de varios proyectos y del Grupo SOCMEDIA (UCM). Además, ha coordinado numerosos libros en editoriales SPI y ha escrito varios libros, capítulos y artículos en publicaciones SPI, JCR y SJR.

fgarciag@ucm.es

Índice H: 61

Orcid ID: 0000-0001-5394-4804

Google Scholar: https://scholar.google.es/citations?hl=es\&user=as2gqFUAAAAJ

ResearchGate: https://www.researchgate.net/profile/Francisco-Garcia-20

Scopus ID: 55439107500

Academia.edu: https://ucm.academia.edu/FranciscoGarc\%C3\%ADaGarc\%C3\%ADa 